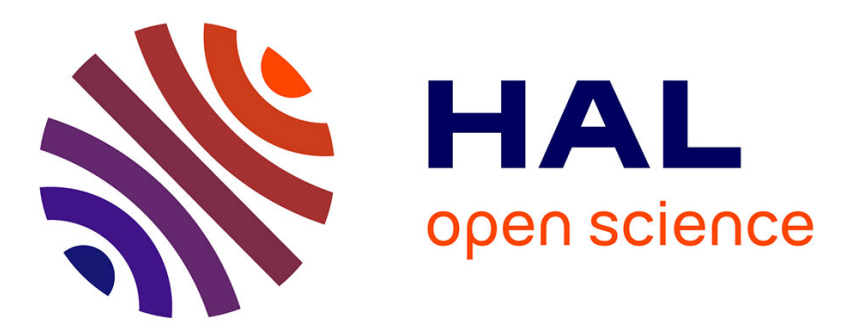

\title{
Microwave Power Harvesting for Satellite Health Monitoring
}

Alexandru Takacs, Hervé Aubert, Stéphane Fredon, Laurent Despoisse, H Blondeaux

\section{- To cite this version:}

Alexandru Takacs, Hervé Aubert, Stéphane Fredon, Laurent Despoisse, H Blondeaux. Microwave Power Harvesting for Satellite Health Monitoring. IEEE Transactions on Microwave Theory and Techniques, 2014, 62 (4), pp.1090-1098. 10.1109/TMTT.2014.2303425 . hal-02066227

\section{HAL Id: hal-02066227 https://hal.laas.fr/hal-02066227}

Submitted on 13 Mar 2019

HAL is a multi-disciplinary open access archive for the deposit and dissemination of scientific research documents, whether they are published or not. The documents may come from teaching and research institutions in France or abroad, or from public or private research centers.
L'archive ouverte pluridisciplinaire HAL, est destinée au dépôt et à la diffusion de documents scientifiques de niveau recherche, publiés ou non, émanant des établissements d'enseignement et de recherche français ou étrangers, des laboratoires publics ou privés. 


\title{
Microwave Power Harvesting for Satellite Health Monitoring
}

\author{
Alexandru Takacs, Member, IEEE, Herve Aubert, Senior member, IEEE, Stephane Fredon, \\ Laurent Despoisse, Henri Blondeaux
}

\begin{abstract}
This paper addresses the microwave energy harvesting on board of geostationary satellites for health satellite monitoring. To prove the feasibility of such a concept, we investigated the electromagnetic environment existing on antenna panels. Based on established cartographic maps, three designs of rectennas are proposed. Measured DC powers ranging from $0.256 \mathrm{~mW}$ to $1.28 \mathrm{~mW}$ can be harvested for electric field levels ranging from $91 \mathrm{~V} / \mathrm{m}$ to $121 \mathrm{~V} / \mathrm{m}$ and by using very simple and compact designs. The harvesting structures consist of only one Schottky diode per rectenna and present a total surface of $\mathbf{2 . 4}$ $\mathrm{cm}^{2}$. They are suitable for powering the new generation of ultralow power transceivers, thus enabling autonomous wireless power networks for satellite health monitoring.

Index Terms-Energy harvesting, rectennas, satellite applications, microwave circuits, autonomous wireless sensors.
\end{abstract}

\section{INTRODUCTION}

$\mathrm{H}$ EALTH MONITORING is a key issue for any satellite application and especially for the implementation of reliable and long-life satellite-based broadcasting links. In order to provide reliable and high bit rate broadcasting links, high gain microwave antennas operating in $\mathrm{C}, \mathrm{X}, \mathrm{Ku}, \mathrm{K}$ or Ka band are used. These antennas are located on panels positioned on the external surface of the satellite. Surveying the health of these panels involves the use of sensors (e.g. for thermal or for mechanical/structural monitoring) deployed in small networks to cover the targeted surface. A very promising solution is to implement small autonomous wireless sensor networks saving the cost of deploying long wires in harsh environments. In some areas located on antenna panels of broadcasting satellites, the electric field generated by the spill-over loss of microwave antennas can reach the following maximum levels (effective values): $40 \mathrm{~V} / \mathrm{m}$ in C-band, 49.5 $\mathrm{V} / \mathrm{m}$ in X-band, $106 \mathrm{~V} / \mathrm{m}$ in Ku-band and $127 \mathrm{~V} / \mathrm{m}$ in K-band. These high-frequency electromagnetic field levels are unusual for terrestrial applications, but they are available on satellites if data links are functional and can be harvested in order to power autonomous wireless sensors used for monitoring the structural health of the satellite. Moreover, the electromagnetic power radiated by microwave antennas is almost constant and consequently the DC power regulatory circuits should be minimal for harvesting systems.

The electromagnetic environment of the antenna panels is analyzed in Section II. Rectenna (RECTifier antENNA) topologies [1] and design methodology developed for proving the concept of microwave power harvesting for satellite health monitoring are discussed in Section III. The main goal of this paper is to demonstrate that microwave energy harvesting based on specific rectenna designs is an ideal solution for powering autonomous sensors for satellite health monitoring.

\section{ELECTROMAGNETIC ENVIRONMENT}

Broadcasting satellite antennas operating in $\mathrm{C}, \mathrm{X}, \mathrm{Ku}$ and $\mathrm{K}$ band radiate electromagnetic power between $50 \mathrm{~W}$ and $100 \mathrm{~W}$ with linearly or circularly polarized electromagnetic field. Recently, Thales Alenia Space (C) performed an analysis of the electromagnetic energy illuminating antenna panels. Intensive electromagnetic simulations using GRASP software from TICRA [2] were performed by taking into account the case of a Spacebus class $\mathrm{C}$ satellite. Figs. 1 to 4 show typical electromagnetic field levels (E-field in $\mathrm{V} / \mathrm{m}$, peak values) on panels located on the lateral side or on the Earth side of a broadcasting geostationary satellite. These levels were obtained in $\mathrm{C}, \mathrm{Ku}$ and $\mathrm{K}$ frequency bands. We observed that large areas of antenna panels are covered with field levels higher than $4 \mathrm{~V} / \mathrm{m}$. This electromagnetic field available at the surface of antenna panels can be advantageously harvested by using rectennas [3] for supplying power to autonomous sensors dedicated to satellite health monitoring. As shown in Fig. 3 a maximum E-field level of $180 \mathrm{~V} / \mathrm{m}$ (peak value) can be reached at $17.7 \mathrm{GHz}$.

This work was supported by French Space Agency (CNES) under research grant R\&T n ${ }^{\circ} 115052$ and R\&T2012 RS12/MT-0002-012.

A. Takacs and H. Aubert are CNRS, LAAS, 7 avenue du colonel Roche, F31400, Toulouse, France and with University of Toulouse, F-31400, Toulouse, France (emails : atakacs@laas.fr, haubert@laas.fr).

S. Fredon is with French Space Agency (CNES), Toulouse, France (email stephane.fredon@cnes.fr).

L. Despoisse and H. Blondeaux are with Thales Alenia Space, Cannes, France (email: laurent.despoisse@thalesaleniaspace.com and henri.blondeaux@thalesaleniaspace.com). 


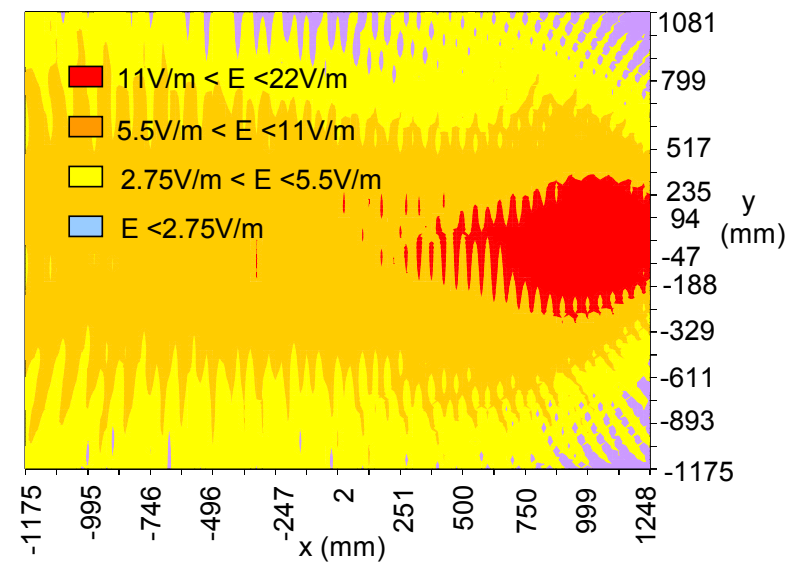

Fig. 1. E-field distribution (peak value) on a lateral panel at $3.5 \mathrm{GHz}$ (C-band). Radiated power: $90 \mathrm{~W}$. The $\mathrm{x}$ - and $\mathrm{y}$-coordinates are in millimeter.

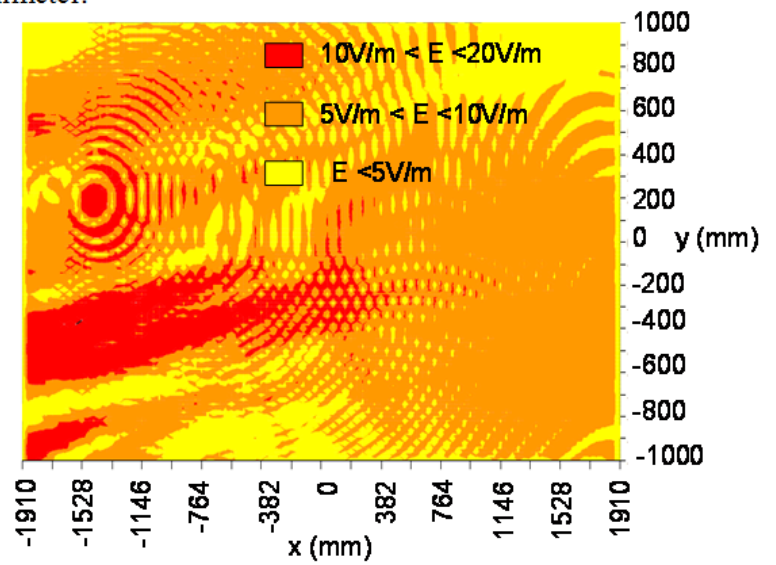

Fig. 2. E-field distribution (peak value) on a lateral panel at 10.7 $\mathrm{GHz}$ (Ku-band). Radiated power: $86.5 \mathrm{~W}$. The $\mathrm{x}$ - and $\mathrm{y}$-coordinates are in millimeter.

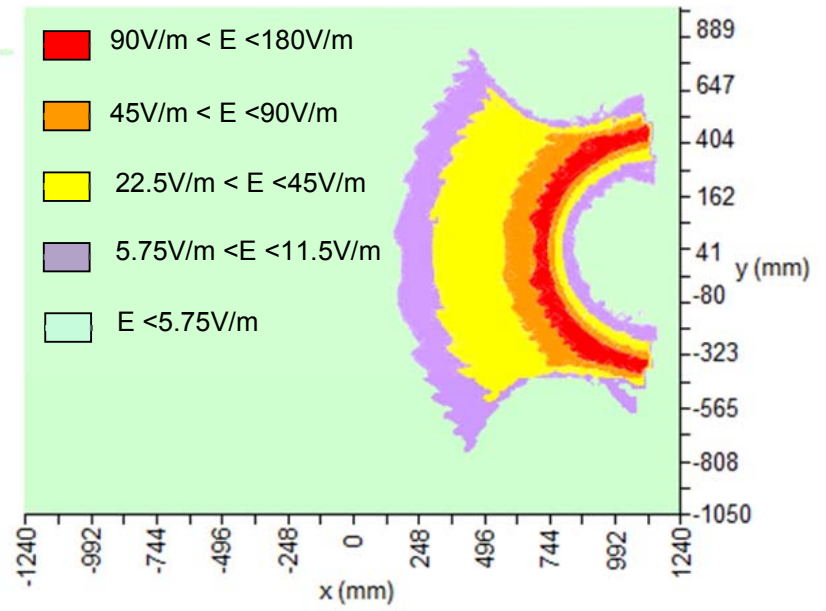

Fig. 3. E-field distribution (peak values) on Earth side of satellite at $17.7 \mathrm{GHz}$. Radiated power: $70 \mathrm{~W}$. The $\mathrm{x}$ - and y-coordinates are in millimeter.

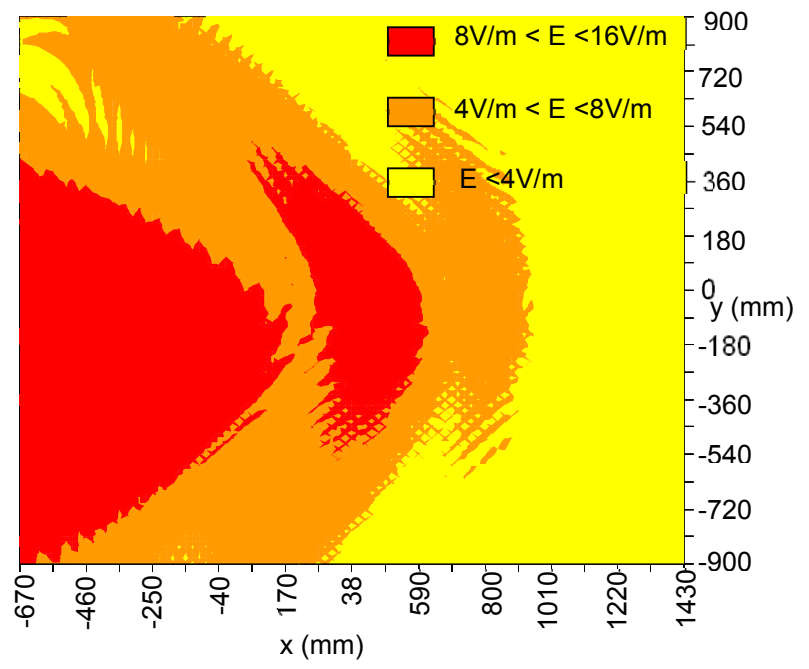

Fig. 4. E-field distribution (peak values) on a lateral side of satellite at $21.4 \mathrm{GHz}$. Radiated power: $85 \mathrm{~W}$ and. The $\mathrm{x}$ - and $\mathrm{y}-$ coordinates are in millimeter.

As shown previously (Fig. 1 to Fig. 4) satellite panels can be illuminated with electromagnetic energy at various frequencies. Moreover the incident waves illuminating satellite panels arrives various directions and have various polarizations (dependently on satellite antennas types and their mounting position). Thus the antenna of the rectenna has to be engineered to meet these criteria (operating frequency, polarization and radiation pattern shape/tilt angle) in order to maximize the amount of the RF power injected at the input of the (rectenna) rectifier.

\section{Microwave Rectennas: Design And MeASurement RESULTS}

Rectennas are intensively used for wireless power transfer or energy harvesting applications. Many designs and topologies have been proposed for various applications, such as GSM [4], GPS [5], C-band (ISM 2.45 GHz) [6]-[10], 5.8 $\mathrm{GHz}[10]$ and X-band [11],[12] applications. Dual-band [9] or broadband [12] designs have been studied while applications beyond $10 \mathrm{GHz}$ have been addressed in the past mainly for wireless power transfer [13] application [3],[14]-[15] but not for power harvesting because of the lack of powerful environmental electromagnetic sources for terrestrial applications. Several research works have been reported on the rectenna design for energy harvesting at frequencies higher than $10 \mathrm{GHz}$ [16]-[19]. A reconfigurable rectenna device that is capable of adapting itself to the incident power level is described in [20]. In order to evaluate the feasibility of such microwave energy harvesting, several rectennas were designed and the measured DC power was compared with typical power requirements for wireless transceivers. Note that ultra-low power receivers are now available [21] and their power consumption is around $2 \mathrm{~mW}$ only (voltage supply of $1.2 \mathrm{~V}$ $1.8 \mathrm{~V}$ with current below $2 \mathrm{~mA}$ ). 


\section{A. Rectenna topology}

In order to keep the proposed designs compatible with the specific technical requirements for space applications, several design guidelines were adopted: (i) the rectenna topology has to be as simple as possible; (ii) all the components in the rectenna (dielectric substrate, diode, capacitors, etc) must be qualified for space applications, ready to be qualified or at least with performances compatible with space requirements; (iii) the operating frequencies must be chosen by taking into account the electromagnetic environment existing on board of satellite antenna panels (typical E-field distributions were presented in Section II) and, (iv) a non-optimal DC loading for rectenna could be chosen, in this a worst case scenario the input impedance/resistance of the sensors and/or the transceiver to be powered may be far from the optimal DC load that maximizes the DC power generated by the rectenna. Keeping in mind these design requirements, the rectenna was designed to power a temperature sensor (load) with a typical resistance in the range of 9-10 k $\Omega$. The rectenna was fabricated on Rogers 6002 substrate (relative permittivity: 2.94, loss tangent: 0.0012 , thickness: $508 \mu \mathrm{m}$, metallization thickness: $35 \mu \mathrm{m}$ ) [22]. Two GaAs flip chip Schottky diodes were selected: M/A Com MA4E-1317 diode [23] and Aeroflex/Metelics MZBD-9161 diode [24]. These diodes were chosen based on their RF power handling, thermal capabilities and high operating frequency. An important issue in rectenna design is the antenna that should: (i) match the polarization of the incident electromagnetic field, (ii) have a gain as high as possible in order to increase rectenna conversion efficiency, (iii) present a high large half-power beamwidth to efficiently operate for various directions of the incident field and, (iv) be easily matched to the rectifier at the operating frequency. Reproducing in Laboratory the electromagnetic environment existing on satellite panels is not an easy task. As presented in Section III.C, by using the setup S2 an incident wave illuminating the rectenna under test with a linearly polarized E-field, with various power densities (E-field levels) and at various frequencies can be easily generated in Laboratory. Consequently we selected (for our rectennas designs) linearly polarized antennas with at least $50^{\circ}$ half-power beam-width and a maximum gain of at least $4 \mathrm{dBi}$.

The proposed rectenna designs are based on the topology shown in Fig. 5. The antenna collects the surrounding electromagnetic power density and transfers it at the input of the rectifier (Schottky diode) through a matching circuit. The matching circuit allows the conjugate impedance matching and maximizes the RF power level flowing from the antenna to the rectifier. Moreover, the matching circuit should stop the reflected power at the operating frequency and harmonics to be radiated by the antenna. The rectifier converts the RF power to a DC power. The DC power is injected into the load through a low-pass filter that blocks any undesirable RF signal at operating frequency or harmonics. In order to facilitate the testing and debugging of such a rectenna, a $50 \Omega$ test point (end-launch $\mathrm{K}$ connector) was added between the antenna and the matching circuit. Although it may introduce undesirable losses and impedance mismatch, this $50 \Omega$ test point was very useful in the early stages of the design.

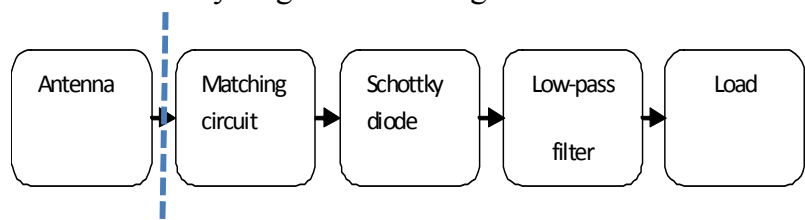

Fig. 5. Rectenna topology: the vertical dotted line indicates the position (reference plane) of the $50 \Omega$ test point (end-launch $\mathrm{K}$ connector).

Based on the topology sketched in Fig. 5, three rectennas were designed, fabricated and measured. These rectennas, named R1 (R1a and R1b), R2 (R2a and R2b) and R3 (R3a and $\mathrm{R} 3 \mathrm{~b}$ ), are shown in Fig. 6. The rectennas R1a (using the MA4E-1317 diode) and R1b (using the MZBD-9161 diode) were the first developed demonstrator. Only the rectifier and its $50 \Omega$ input port are shown in Fig. 6. They used only a single stub matching circuit and a lumped RC low-pass filter. The $10 \mathrm{k} \Omega$ load impedance is integrated in the filter structure. The results obtained with these simple topologies were recently reported by the authors [16]. The main drawback of the R1rectenna is its low efficiency at $17.7 \mathrm{GHz}$ and consequently a high gain (horn) antenna is needed for harvesting a DC power higher than $2 \mathrm{~mW}$. Two new rectenna designs named $\mathrm{R} 2$ and R3 with improved harvesting performances were developed and are now presented.
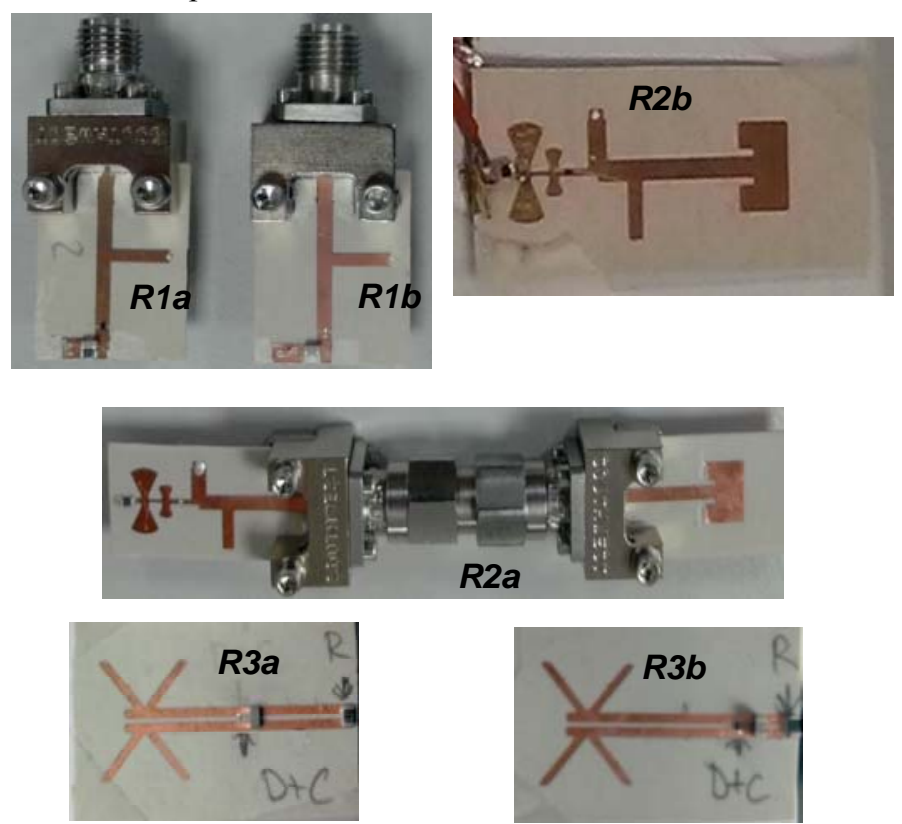

Fig. 6. Photos of the developed rectenna designs: R1 (R1a and R1b), R2 (R2a and R2b) and R3 (R3a and R3b)

The rectenna R2 uses the MA4E-1317 diode, a double stub matching circuit and a distributed low-pass filter containing two radial stubs. The radial stubs were designed for rejecting the operating frequency $(17.7 \mathrm{GHz})$ and the second-order harmonic (35.4 GHz). The rectenna R2a was composed of a rectifier and a patch antenna having a gain around $4 \mathrm{dBi}$. The rectifier and the antenna are connected using a K-adapter. The 
$50 \Omega$ test point allows characterizing the rectifier and the antenna performances separately. This test point was eliminated in the rectenna $\mathrm{R} 2 \mathrm{~b}$. The rectenna $\mathrm{R} 3$ is more compact. A similar topology, based on dual dipole like (DDL) antenna and operating at $2.45 \mathrm{GHz}$, was proposed in [9]. The antenna was excited by a coplanar stripline. No matching circuit was necessary, and the maximum power transfer (between antenna and diode/rectifier input) and the suppression of the undesirable reflected power at the second harmonic were achieved by properly controlling the input impedance of the antenna. A capacitance of $1.5 \mathrm{pF}$ was used for shunting the RF signal at the operating frequency and its harmonics. In order to maximize the performances of this design, it is crucial to properly control the diode mounting position.

\section{B. Rectennas design and simulation methodology}

One of the major challenges in the effective design of rectennas in the microwave frequency range $(\mathrm{Ku}$ band and higher) is the accurate non-linear modeling of the diode. The most relevant parameters of the MA4E-1317 diode were derived from an available datasheet [23] (total capacitance: $0.045 \mathrm{pF}$, series resistance: $\mathrm{Rs}=4 \Omega$ ) and from the extrapolation of the $\mathrm{I}-\mathrm{V}$ measured characteristic (derived ideality factor: $n \approx 1.2$ and saturation current: $\mathrm{Is} \approx 0.1 \mathrm{pA}$ ). For the MZBD-9161 diode, the Spice equivalent model proposed in [24] was used but with a much lower breakdown voltage (3.5 V instead of the $10 \mathrm{~V}$ given in the datasheet). A lower breakdown voltage was needed to accurately model the observed nonlinear power behavior of the diode. The simulation model for the MZBD-9161 diode given in [24] uses two anti-parallel diodes (with different parameters) in order to simulate the single Schottky diode used in the rectenna. Fig. 7 shows the complete simulation model in AWR software [25] for the rectenna R2 (without the patch antenna) using closedform models for the distributed components (transmission lines, stubs and via hole).

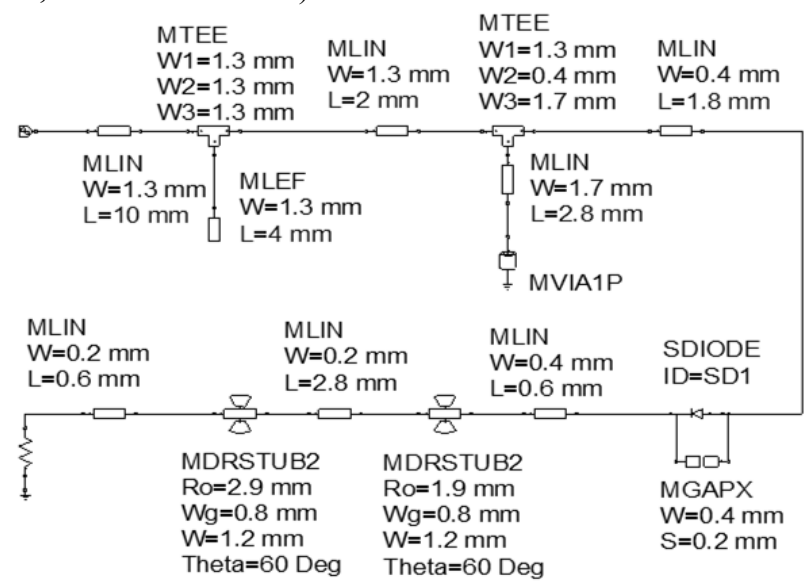

Fig. 7. Simulation model (AWR) of the rectenna R2a (without patch antenna) and its dimensions.

The harmonic balance simulation engine was used for performing non-linear simulations. A generic non-physical diode model available in AWR software [25] was customized with the MA4E-1317 and MZBD-9161 diode parameters. The rectangular patch antenna was designed, simulated and optimized using the HFSS antenna design kit [26].

The design procedure for the design of the rectenna R3 was quite different. First the DDL antenna was designed and simulated using FEKO [27] for operation at the desired frequency $(17.7 \mathrm{GHz})$. The antenna radiation pattern, gain and radiation efficiency were calculated and the distribution of the electric currents on the metallic strips were analyzed. The design requires a low load resistance for working efficiently. A load of $510 \Omega$ was used. For simulation purposes, the diode was replaced by a voltage port while the capacitance $(1.5 \mathrm{pF})$ and the load (510 $\Omega$ ) were modeled as port loads. Fig. 8 shows a top view of the rectenna R3. The dimensions of the R3 design are: $l_{x}=20 \mathrm{~mm}, l_{y}=14 \mathrm{~mm}, l_{d}=5.5 \mathrm{~mm}, l_{r}=15 \mathrm{~mm}$, $l_{s}=1.4 \mathrm{~mm}, l_{a x}=6.3 \mathrm{~mm}$ and $l_{a y}=8.3 \mathrm{~mm}$. The coplanar strip line is characterized by a strip width of $w=0.8 \mathrm{~mm}$ and a gap size of $g=0.4 \mathrm{~mm}$. A metallic plate (dotted line contour in the Fig. 8) was printed below the radiating element $\left(l_{g x}=10 \mathrm{~mm}\right.$ and $\left.l_{y}=14 \mathrm{~mm}\right)$. R3 design is very compact with a total surface of $2.4 \mathrm{~cm}^{2}$.

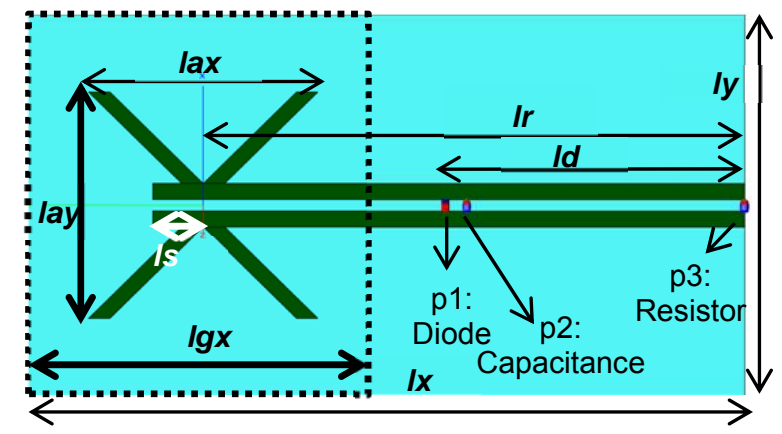

Fig. 8. Simulation model (Feko) of the R3-rectenna design (see the text for the dimensions)

\section{Experimental setup}

Two experimental setup configurations, named S1 and S2, were used. In the $\mathrm{S} 1$ setup shown in Fig. 9 a continuous millimeter-wave signal generated from an Anritsu MG3694B generator was directly injected at the $50 \Omega$ test point of the manufactured prototypes and the resulting DC voltage was measured at the input port of the load impedance with a Keythley 2000 multimeter.

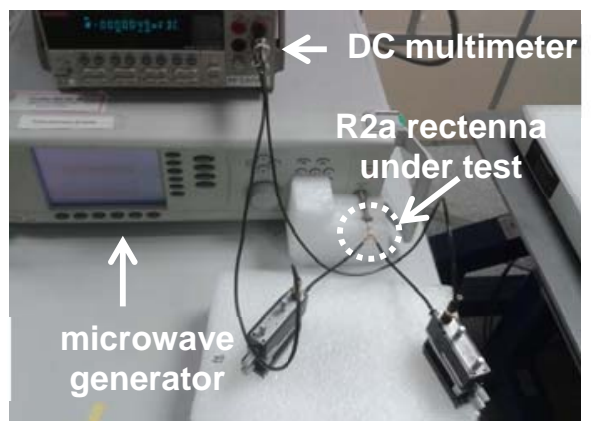

Fig. 9. Setup S1.

The setup ( $\mathrm{S} 1)$ is appropriate for testing the rectifier part 
(e.g. R1a, R1b, R2a) of the rectennas when equipped with a $50 \Omega$ test point (coaxial $\mathrm{K}$ connector). In the S2 setup shown in Fig. 10, a microwave signal generated from an Anritsu MG3694B generator was injected at the input of a horn antenna (VT220HA20-SK from Vector Telecom [28]) which illuminated the rectenna under test with a linear polarized Efield. This setup is appropriate for testing the rectennas (R2b, R3) or rectifiers equipped with a $50 \Omega$ test point/coaxial $\mathrm{K}$ connector (e.g. R1a, R1b, R2a) connected with an external antenna.

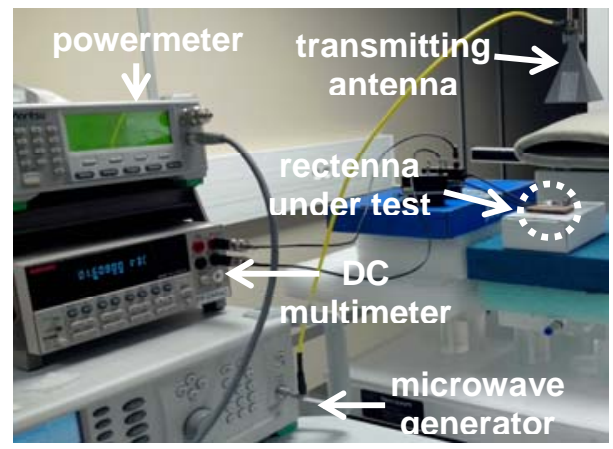

Fig. 10. Setup S2.

An automatic acquisition routine was implemented in Labview software from National Instruments [29] in order to speed-up the acquisition process. The harvested DC voltage was measured with the microwave source OFF (DC noise: V_off) and with microwave source $\mathrm{ON}$ (DC voltage: V_on). The DC voltage of interest (Vout) was then derived from the difference Vout $=$ V_on - V_off. Digital filters were used for minimizing the noise level. The measurement was performed twice and the average value of Vout was registered as the final result.

\section{Simulation and experimental results}

The layouts of rectennas were accommodated with the tolerances required by a fabrication in a laboratory equipped for general-purpose printed circuit boards (PCB). A solid silver-filled epoxy system EPO-TEK ${ }^{\circledR} \mathrm{H} 20 \mathrm{E}$ was used for soldering the diodes by a low temperature process $\left(110^{\circ} \mathrm{C}\right)$.

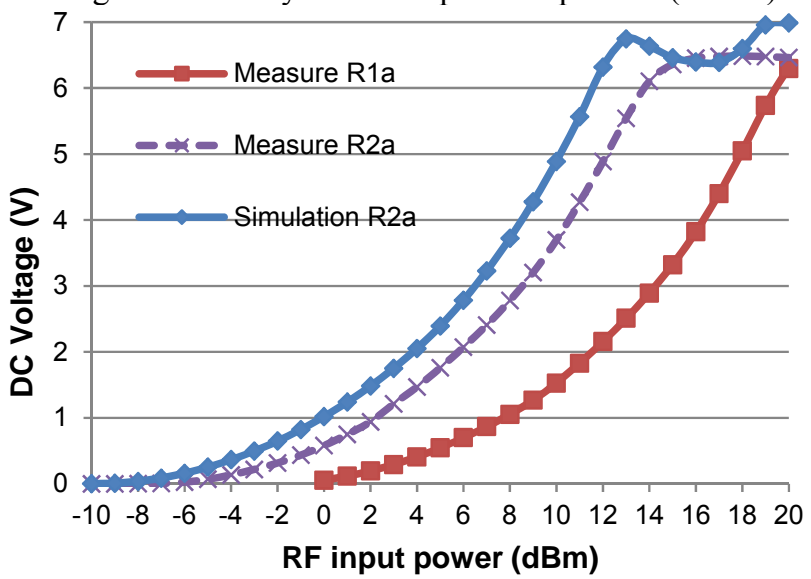

Fig. 11. Measured DC output voltages (setup S1) for R1a (dotted red line, square marker) and $\mathrm{R} 2 \mathrm{a}$ (dotted violet line, ' $\mathrm{x}$ ' marker design).
The simulation results obtained by using AWR simulation model for $\mathrm{R} 2 \mathrm{a}$ are represented with a continuous (blue) line (diamond marker).

Fig. 11 and Fig. 12 show a comparison between the measured performances (by using the setup S1) of the rectifiers $\mathrm{R} 1 \mathrm{a}$ and $\mathrm{R} 2 \mathrm{a}$ in terms of the harvested $\mathrm{DC}$ voltage (Fig. 11) and DC power (Fig. 12) at the input of the load impedance $(10 \mathrm{k} \Omega)$.

A DC voltage up to $6.4 \mathrm{~V}$ and a DC power up to $4 \mathrm{~mW}$ can be harvested with the R2a design when a RF power around 15 $\mathrm{dBm}$ is injected at the input of the rectifier (Schottky diode). A maximum worst-case efficiency of $15.4 \%$ was achieved for a $\mathrm{RF}$ input power of $13 \mathrm{dBm}$ (experimental results). This worst case efficiency takes into account the losses and the impedance mismatch introduced by the $50 \Omega \mathrm{K}$-connector and by the male-to-male $\mathrm{K}$-adapter. This low efficiency is mainly due to the non-optimal load impedance $(10 \mathrm{k} \Omega)$ chosen as reference.

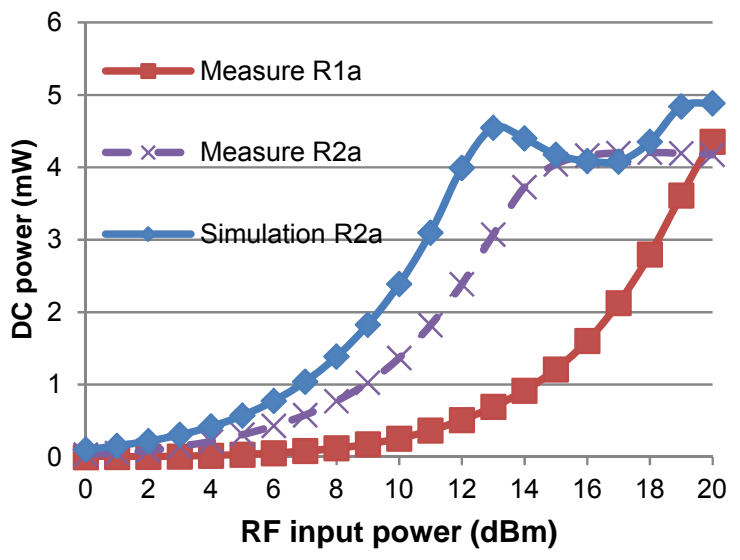

Fig. 12. Measured DC output power (setup S1) for R1a (dotted red line, square marker) and $\mathrm{R} 2 \mathrm{a}$ (dotted violet line, ' $\mathrm{x}$ ' marker design). The simulation results obtained by using AWR simulation model for $\mathrm{R} 2 \mathrm{a}$ are represented with a continuous (blue) line (diamond marker).

Precursory of the R1a/R1b structures, reported in [30]-[31] were tested in CNES (French Space Agency) Laboratory by applying a standard thermal cycling procedure for space applications (30 thermal cycles performed between $-65^{\circ} \mathrm{C}$ and $+125^{\circ} \mathrm{C}$ ). Despite of the soldering-free home-made fixation system the prototypes still remained operational after the thermal cycling without a major impact on the RF performances.

The output DC voltage as a function of the operating frequency obtained for a RF input power of $13 \mathrm{dBm}$ is displayed in the Fig. 13. The maximum voltage of $5.4 \mathrm{~V}$ was obtained at $17.7 \mathrm{GHz}$, which is the central operating frequency of the single stub matching circuit. 


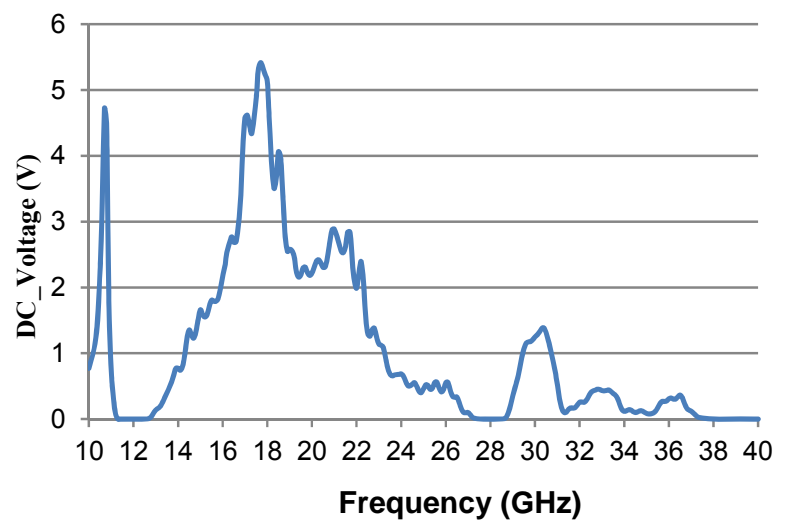

Fig. 13. Measured DC output voltage (setup S1) for R2a design as a function of the frequency for an RF power of $13 \mathrm{dBm}$ at the input of $50 \Omega$ test point.

Fig. 14 shows the measured DC voltage harvested by the R2b-rectenna design when illuminated with the electric field of a horn antenna (gain: $18.6 \mathrm{dBi}$ at $17.7 \mathrm{GHz}$ ). A microwave power ranging from 10 to $24 \mathrm{dBm}$ was injected at the input of the horn antenna. The distance between the radiating aperture of the horn antenna and the rectenna $\mathrm{R} 2 \mathrm{~b}$ is $15 \mathrm{~cm}$. The input port (coaxial $\mathrm{K}$ connector) of the transmitting horn antenna is located at $25 \mathrm{~cm}$ above the rectenna $\mathrm{R} 2 \mathrm{~b}$ under test. A maximum DC voltage of $1.6 \mathrm{~V}$ was measured and a low harvested DC power of $0.256 \mathrm{~mW}$ was obtained. In order to measure the RF power collected by the patch antenna, a calibrated Anritsu ML2437A powermeter was used. The measured RF power received with the patch antenna alone (gain: $5 \mathrm{dBi}$ at $17.7 \mathrm{GHz}$ ) was found to be $4.5 \mathrm{dBm}$ : when this $\mathrm{RF}$ power was directly injected at the input port of the rectifier (using the $50 \Omega$ test point of R2a in the setup S1), the harvested DC voltage was found to be $1.63 \mathrm{~V}$. Consequently, the measurement results obtained using setup S2 (Fig. 14) are coherent with the results depicted in Fig. 11.

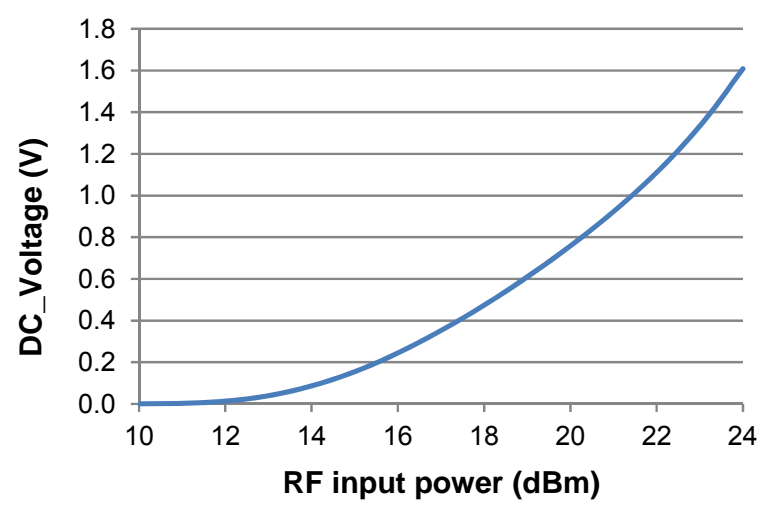

Fig. 14. Measured DC output voltage (setup S2) for the R2brectenna design as a function of the RF power injected at the input port of a transmitting (horn) antenna (operating frequency: 17.7 $\mathrm{GHz}$ ).

To obtain a harvested DC power higher than $2 \mathrm{~mW}$, an antenna with a gain of at least $12 \mathrm{dBi}$ should be used instead of the patch antenna. Alternatively a DC combining circuit could be proposed to combine the DC power harvested from many rectennas [1].

The power $\mathrm{P}$ received at a given frequency by an antenna of gain $\mathrm{G}$ at a location where an electric field level $\mathrm{E}$ exists can be approximated by [32]:

$$
P=\frac{E^{2}}{120 \cdot \pi} \cdot \frac{G \cdot \lambda^{2}}{4 \cdot \pi}
$$

where $\lambda$ denotes the free-space wavelength. Consequently, the RF power at the output of the receiving antenna (input of the $50 \Omega$ test point) can be estimated for a given incident E-field level (table 1). Eq. (1) can be also written as:

$$
E=\frac{2 \cdot \pi}{\lambda} \cdot \sqrt{\frac{120 \cdot P}{G}}
$$

When specifying the required RF power at the output of a calibrated antenna (with a known gain), the needed E-field level can then be derived from Eq.(2). Three typical antenna gains were considered: $18.6 \mathrm{dBi}$ (e.g. horn antenna), $11 \mathrm{dBi}$ (for comparison purposes) and $5 \mathrm{dBi}$ (e.g. patch antenna).

Table 1: Estimated RF power at the input of the $50 \Omega$ test point, measured DC voltage extracted from Fig. 11 and the computed DC power for $\mathrm{R} 2 \mathrm{a}$ design $(\mathrm{f}=17.7 \mathrm{GHz})$

\begin{tabular}{|c|c|c|c|c|}
\hline & & & \multicolumn{2}{|c|}{ R2a design (MA4E-1317) } \\
\cline { 4 - 5 } E (V/m) & G (dBi) & $\begin{array}{c}\text { RF power } \\
(\mathbf{d B m})\end{array}$ & $\begin{array}{c}\text { DC voltage } \\
\mathbf{( V )}\end{array}$ & $\begin{array}{c}\text { DC power } \\
(\mathbf{m W})\end{array}$ \\
\hline 107 & 18.6 & 17 & 6.48 & 4.2 \\
\hline 67 & 18.6 & 13 & 5.54 & 3.07 \\
\hline 48 & 18.6 & 10 & 3.67 & 1.37 \\
\hline 34 & 18.6 & 8 & 2.78 & 0.77 \\
\hline 27 & 18.6 & 5 & 1.75 & 0.31 \\
\hline 15 & 18.6 & 0 & 0.58 & 0.033 \\
\hline 127 & 11 & 10.9 & 4.27 & 1.82 \\
\hline 91 & 11 & 8 & 2.78 & 0.77 \\
\hline 72 & 11 & 6 & 2.07 & 0.43 \\
\hline 51 & 11 & 3 & 1.21 & 0.015 \\
\hline 36 & 11 & 0 & 0.58 & 0.033 \\
\hline 127 & 5 & 4.9 & 1.75 & 0.31 \\
\hline 121 & 5 & 4.5 & 1.6 & 0.28 \\
\hline 114.5 & 5 & 4 & 1.47 & 0.21 \\
\hline 102 & 5 & 3 & 1.21 & 0.015 \\
\hline 91 & 5 & 2 & 0.94 & 0.088 \\
\hline 72 & 5 & 0 & 0.58 & 0.033 \\
\hline
\end{tabular}

To design rectenna $\mathrm{R} 3$, the variation of the input impedance of DDL antenna as a function of the diode mounting position was analyzed. The simulated input impedance $Z_{\text {in }}$ of the antenna viewed at the distance $l_{r}-l_{d}$ along the coplanar stripline is depicted in Fig. 15 as a function of $l_{d}$ (see Fig. 7). The imaginary part (reactance) was found to be positive. As the estimated input impedance of the MZBD-9161 diode is 8 $\mathrm{j} * 80 \Omega$ the diode should be located approximately at $1_{d}=5.5$ $\mathrm{mm}$ to ensure the conjugate impedance matching condition. Moreover since the (simulated) impedance $Z_{\text {in }}$ at $l_{d}=5.5 \mathrm{~mm}$ is $24.5+\mathrm{j} * 130 \Omega$ at $35.4 \mathrm{GHz}$ (i.e., at the first harmonics) and 
$204+j * 203 \Omega$ at $53.1 \mathrm{GHz}$ (i.e., at the second harmonics), the reflected power radiated back by the antenna of the rectenna (R3 design) is expected to be small at the first two higherorder harmonics.

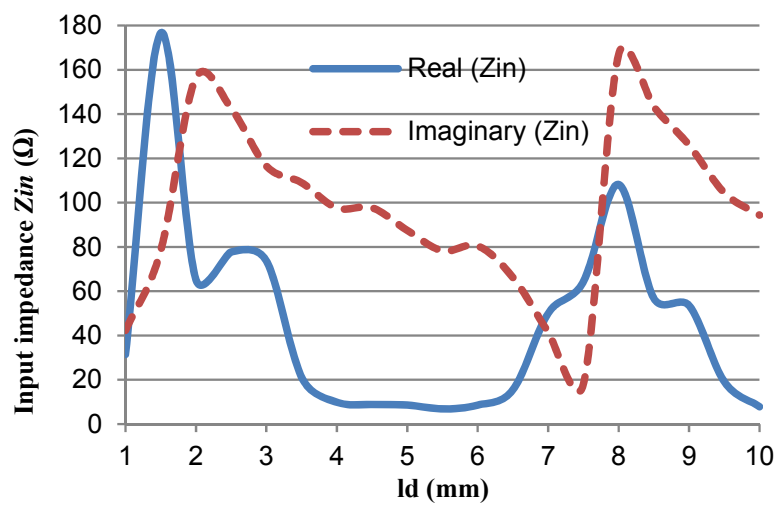

Fig. 15. Simulated input impedance $Z_{\text {in }}$ of the antenna (R3 design) viewed at the distance $l_{r}-l_{d}$ along the coplanar stripline as a function of $l_{d}$.

The simulated radiation pattern displayed in Fig. 16 shows that the maximum gain of the DDL antenna is approximately 6 dBi.

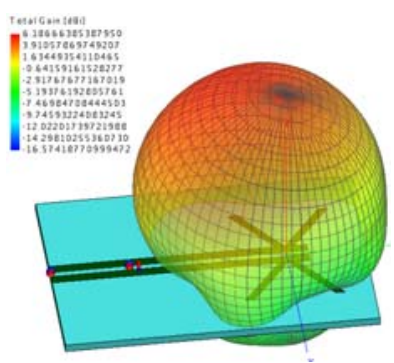

(a)

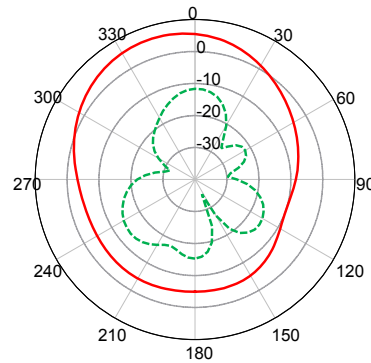

(b)
Fig. 16. Simulated radiation pattern (gain) of rectenna R3a: a) 3D radiation pattern and b) E-plane polar cut: main (E_phi) and cross (E_theta) components of the total gain (values in $\mathrm{dB}$, angles in degrees) are represented with continuous (red) and dotted (green) lines, respectively.

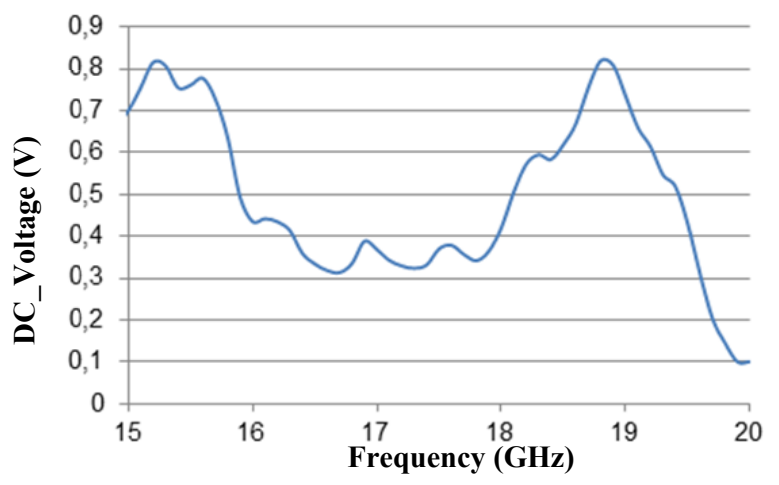

Fig. 17. Measured DC voltage (S2 setup) at the input of the load $(510 \Omega)$ as a function of the frequency (R3 design).
The measured DC voltage (setup S2, power injected at the input of a horn antenna: $23 \mathrm{dBm}$, distance between the horn aperture and the $\mathrm{R} 3 \mathrm{a}$ rectenna: $\mathrm{d}=15 \mathrm{~cm}$ ) as a function of the frequency is depicted in Fig. 17.

A maximum DC voltage of $0.81 \mathrm{~V}$ (DC power of $1.28 \mathrm{~mW}$ ) was recorded at a frequency of $18.8 \mathrm{GHz}$ while a DC voltage of only $0.36 \mathrm{~V}$ (DC power of $0.25 \mathrm{~mW}$ ) is measured at the targeted operating frequency $\mathrm{f}=17.7 \mathrm{GHz}$. This can be explained by: (i) the inaccuracy of the adopted design methodology (in the electromagnetic model the antenna is loaded by a voltage electromagnetic port instead of the actual nonlinear loading of the diode); (ii) manufacturing tolerances (all the rectennas were fabricated in an university laboratory not equipped for high-frequency PCB manufacturing); (iii) error in the positioning of the diode during its mounting on the $\mathrm{PCB}$. However the rectenna R3a is very compact $\left(2.8 \mathrm{~cm}^{2}\right)$ and performs very well in a very wide frequency range (from 15 to $20 \mathrm{GHz}$ ). The measured RF power (using a calibrated Anritsu ML2437A powermeter) at the output of manufactured patch antenna is $2 \mathrm{dBm}$ and is consistent with the E-field level of $91 \mathrm{~V} / \mathrm{m}$ at $17.7 \mathrm{GHz}$ estimated on the rectenna surface. In order to calculate the efficiency $\eta$ (in \%) of this rectenna the following worst case definition is used [7], [33]:

$$
\eta=\frac{P_{D C}}{S \cdot A_{G}} \cdot 100
$$

where $\mathrm{P}_{\mathrm{DC}}$ is the measured harvested $\mathrm{DC}$ power, $\mathrm{S}$ is the incident power density and $\mathrm{A}_{\mathrm{G}}$ denotes the area of the radiating surface. The power density (expressed in $\mu \mathrm{W} / \mathrm{cm}^{2}$ ) can be computed as function of E-field effective value $E$ on the antenna surface as follows:

$$
S=\frac{E^{2}}{120 \cdot \pi} \cdot 100
$$

In the case of the R3 design an efficiency of $42 \%$ is derived for $\mathrm{A}_{\mathrm{G}}=1.4 \mathrm{~cm}^{2}$ and $\mathrm{E}=91 \mathrm{~V} / \mathrm{m}$ (we consider here that the geometrical surface of antenna is the surface of the metallic plate printed below the DDL radiating element, that is $10 \mathrm{mmx} 14 \mathrm{~mm}$ ). Taking into account the geometrical surface of the patch antenna which is approximately $1 \mathrm{~cm}^{2}$ for the rectenna $\mathrm{R} 2 \mathrm{~b}$ we obtain a worst-case efficiency of $11.4 \%$ $\left(A_{G}=1 \mathrm{~cm}^{2}\right.$ and $\left.E=91 \mathrm{~V} / \mathrm{m}\right)$ according to eq. 3. This low efficiency can be explained by: (i) the non-optimal loading of the MA4E-1317 diode by a $10 \mathrm{k} \Omega$ load and (ii) the MA4E1317 diode (forward voltage in the range of $0.7 \mathrm{~V}$ ) serially connected with the patch antenna requires a high RF input power in order to be properly self-biased and to operate efficiently. This high RF input power cannot be delivered by the patch antenna under the test condition (setup S2, incident E-field : $\mathrm{E}=91 \mathrm{~V} / \mathrm{m})$.

Several rectennas operating at frequencies beyond $10 \mathrm{GHz}$ were reported in the literature [14]-[19]. Table 2 summarizes the performances (efficiency: eff in $\%$ as function of the frequency: $\mathrm{f}$ in $\mathrm{GHz}$ and size in $\mathrm{mm}^{2}$ ) of these rectennas compared with our work. We note that only the references [14]-[15] present measured values (with a setup and 
experimental conditions well detailed) for the overall efficiency of the rectennas.

Table 2: Comparison of the rectennas performances for reported design (beyond of $10 \mathrm{GHz}$ )

\begin{tabular}{|c|c|c|c|c|}
\hline $\begin{array}{c}\text { eff } \\
(\%)\end{array}$ & $\begin{array}{c}\mathbf{f} \\
(\mathbf{G H z})\end{array}$ & Diode & $\begin{array}{c}\text { Size } \\
\left(\mathrm{mm}^{2}\right)\end{array}$ & Note \\
\hline 39 & 35 & $\begin{array}{c}\text { DMK6606 } \\
\text { (Alpha) }\end{array}$ & $>24$ & $\begin{array}{l}\text { [14]: a waveguide array simulation } \\
\text { technique [34] was used to measure } \\
\text { the overall rectenna efficiency; the } \\
\text { reported efficiency defined as the } \\
\text { ratio of DC power to the input power } \\
\text { into diode was measured for } 60 \mathrm{~mW} \\
\text { of input power into the diode and for } \\
\text { an optimum load of } 400 \Omega\end{array}$ \\
\hline 35 & 35 & $\begin{array}{c}\text { M/A Com } \\
\text { MA4E- } \\
1317\end{array}$ & $>110$ & $\begin{array}{l}{[15]: \text { the reported efficiency }} \\
\text { (received RF power/output DC } \\
\text { power) was measured using a free } \\
\text { space setup for an incident power } \\
\text { density of } 30 \mathrm{~mW} / \mathrm{cm}^{2} \text { and for a load } \\
\text { resistance of } 50 \Omega\end{array}$ \\
\hline 54.6 & 24 & $\begin{array}{c}\text { M/A Com } \\
\text { MADS- } \\
\text { 001317- } \\
1320 A G\end{array}$ & $\mathrm{NR}^{*}$ & $\begin{array}{l}\text { [16]: the efficiency was measured by } \\
\text { illuminating the rectenna with a } \\
\text { signal delivered by a waveguide } \\
\text { expander positioned in the close } \\
\text { vicinity of the rectenna under test. } \\
\text { The reported value was obtained for } \\
130 \mathrm{~mW} \text { of RF input power } \\
\text { (supposed to be at the input of the } \\
\text { rectifier) and an optimal load of } 400 \\
\Omega\end{array}$ \\
\hline 82 & 24 & $\begin{array}{c}\text { M/A Com } \\
\text { MA4E- } \\
1317\end{array}$ & $\mathrm{NR}^{*}$ & $\begin{array}{l}\text { [17]: the reported efficiency (for } 5 \\
\text { mW of RF power at the input of the } \\
\text { rectifier) concerns only the } \\
\text { microwave rectifier loaded by an } \\
\text { optimal resistive load (value } \mathrm{NR}^{*} \text { ) }\end{array}$ \\
\hline 17 & 25.7 & $\begin{array}{c}\text { M/A Com } \\
\text { MA4E- } \\
\text { 2502L }\end{array}$ & 328.5 & $\begin{array}{l}\text { [19]: only the efficiency of the } \\
\text { rectifier part is reported; value } \\
\text { obtained for a RF power of } 8 \mathrm{dBm} \text { at } \\
\text { the input of the diode and an optimal } \\
\text { load of } 1500 \Omega\end{array}$ \\
\hline 42 & 18.8 & $\begin{array}{c}\text { Metelics } \\
\text { MZBD- } \\
9161\end{array}$ & 280 & $\begin{array}{l}\text { This paper: the rectenna efficiency } \\
\text { (worst case definition: eq. 3) was } \\
\text { measured by using the setup S2, for } \\
\text { an incident E-field of } 91 \mathrm{~V} / \mathrm{m} \\
\text { (incident power density around of } 2.2 \\
\mathrm{~mW} / \mathrm{cm}^{2} \text { ) and for a load of } 510 \Omega\end{array}$ \\
\hline
\end{tabular}

We note that for lower frequencies (e.g. $2.45 \mathrm{GHz}$ or below) higher efficiencies (up to $80 \%$ ) can be obtained.

\section{CONCLUSION}

We present the cartography of the electromagnetic environment available on antenna panels of broadcasting geostationary satellites. Large areas of those panels are illuminated with an electromagnetic field ranging from $4 \mathrm{~V} / \mathrm{m}$ to $127 \mathrm{~V} / \mathrm{m}$. This electromagnetic energy can be harvested to supply power to wireless sensor networks for satellite health monitoring. In order to prove the feasibility of the concept three rectennas, named R1, R2 and R3, were proposed. The rectennas were developed in a worst case scenario, namely when the rectifier/Schottky diode is not optimally loaded by the DC load impedance. Moreover, constraints concerning the space applications were taken into account in the rectennas design. Measured DC powers ranging from $0.256 \mathrm{~mW}$ (R2 design for an incident E-field level around $121 \mathrm{~V} / \mathrm{m}$ ) to 1.28
$\mathrm{mW}$ (R3 design for an incident E-field around $91 \mathrm{~V} / \mathrm{m}$ ) were harvested. If a higher antenna gain is used in the R2 design, a DC power higher than $2 \mathrm{~mW}$, (i.e. the typical power consumption of the new generation of ultra-low power transceivers) may be harvested. The very compact rectenna (design R3 with a total surface of $2.8 \mathrm{~cm}^{2}$ ) can harvest a DC power around $2 \mathrm{~mW}$ if more electromagnetic energy is available (e.g. if the E-field level reaches $127 \mathrm{~V} / \mathrm{m}$ ). Moreover, the well-known stability of the microwave links will reduce the complexity of any DC power management, storage, or regulatory circuits.

\section{ACKNOWLEDGMENTS}

The authors acknowledge Tonio Idda (former CNRS-LAAS engineer) for his valuable support during the early stage of the project, Samuel Charlot from CNRS-LAAS for diode mounting, the support of the European Commission and of the National Funding Agency (Region Midi-Pyrénées) from France through the MNT-ERA.NET project MEMIS (MEMS based Millimeter wave Imaging System) for developing the simulation model for GaAs Schottky diodes successfully used in the design of our rectennas. The electronic laboratory of University of Toulouse (Paul Sabatier) is acknowledged for PCB manufacturing.

\section{REFERENCES}

[1] Z. Popovic, "Cut the Cord Low-power far-field wireless powering" IEEE Microwave Magazine, pp. 55-62, march/avril 2013

[2] http://www.ticra.com/

[3] W. C. Brown, "The history of power transmission by radio waves," IEEE Trans. Microw. Theory Techn., vol. 32, no. 9, pp. 1230-1242, 1984.

[4] S.Ladan, N. Ghassemi, A. Ghiotto, K. Wu, "Highly Efficient Compact Rectenna for Wireless Energy Harvesting Application", IEEE Microwave Magazine, Vol. 14, Issue: 1, pp. 117-122, 2013.

[5] N. Zhu, R. W. Ziolkowski, H. Xin "Electrically Small GPS L1 Rectennas", IEEE Antennas Wireless Propag. Lett., Vol. 10, pp. 935 938, 2011.

[6] Z. Harouni, L. Cirio, L Osman, A. Gharsallah, O. Picon, "A Dual Circularly Polarized 2.45-GHz Rectenna for Wireless Power Transmission”, IEEE Antennas Wireless Propag. Lett., Vol. 10, pp. 306 $-309,2011$.

[7] Z. Popovic; E.A. Falkenstein, D. Costinett, R. Zane, "Low-Power FarField Wireless Powering for Wireless Sensors", Proceedings of the IEEE, Vol. 101, No. 6, pp.1397-1407, June 2013.

[8] H.J. Visser and R.J.M.Vullers, "RF Energy Harvesting and Transport for Wireless Sensor Network Applications: Principles and Requirements", Proceedings of the IEEE, Volume: 101 , Issue: 6, 1410-1423, 2013.

[9] H. Sun, Y.-X. Guo, M. He, Z. Zhong, "Design of a High-Efficiency 2.45-GHz Rectenna for Low-Input-Power Energy Harvesting”, IEEE Antennas Wireless Propag. Lett., Vol. 11, pp. 929-932, 2012.

[10] Y.-H. Suh and K. Chang, "A high-efficiency dual-frequency rectenna for 2.45- and 5.8-GHz wireless power transmission," IEEE Trans. Microw. Theory Tech., vol. 50, no. 7, pp. 1784-1789, Jul. 2002.

[11] L. W. Epp, A. R. Khan, H. K. Smith, and R. P. Smith, "A compact dual polarized $8.51-\mathrm{GHz}$ rectenna for high-voltage $(50 \mathrm{~V})$ actuator applications," IEEE Trans. Microw. Theory Tech., vol. 48, no. 1, pp. 111-119, Jan. 2000.

[12] A. Hagerty, F.B. Helmbrecht, W.H. McCalpin, R. Zane, Z.B. Popovic, "Recycling ambient microwave energy with broad-band rectenna arrays", IEEE Trans. Microw. Theory Tech., Volume 52, Issue 3, pp. 1014-1024, March 2004.

[13] B. Strassner, K. Chang, "Microwave Power Transmission: Historical Milestones and system Components", Proceedings of the IEEE, Vol. 101, No. 6, pp.1379 -1395, June 2013. 
[14] T.-W. Yoo and K. Chang, "Theoretical and experimental development of 10 and $35 \mathrm{GHz}$ rectennas," IEEE Trans. Microw. Theory Techn., vol.40, no. 6, pp. 1259-1266, Jun. 1992.

[15] Y.-J. Ren, M.-Y. Li, K. Chang, "35 GHz rectifying antenna for wireless power transmission," IET Electronics Letters, vol.43, no.11, pp.602-603, May 242007.

[16] N. Shinohara, K. Nishikawa, T. Seki, K.Hiraga, "Development of 24 $\mathrm{GHz}$ rectennas for Fixed Wireless Access," 2011 URSI General Assembly and Scientific Symp., pp.1-4, 13-20 Aug. 2011.

[17] S. Ladan, and K. Wu, "High Efficiency Low-Power Microwave Rectifier for Wireless Energy Harvesting”, in Proc. IMS'2013, 2013.

[18] A. Takacs, H. Aubert, L. Despoisse, S. Fredon, 'Microwave energy harvesting for satellite applications', IET Electronics Letters, Issue 11, Vol. 49, pp. 722-723, 23 May 2013.

[19] A. Collado, A. Georgiadis, "24 GHz Substrate Integrated Waveguide (SIW) Rectenna for Energy Harvesting and Wireless Power Transmission, in Proc. of IMS'2013, 2013.

[20] V. Marian, B. Allard, C. Vollaire, J. Verdier "Strategy for Microwave Energy Harvesting From Ambient Field or a Feeding Source", IEEE IEEE Trans. on Power Electronics, Vol. 27, No. 11, pp. 4481-4490, Nov. 2012.

[21] http://www.zarlink.com/zarlink/ZL70250_PP_Aug2012.pdf

[22] http://www.rogerscorp.com/documents/609/acm/RT-duroid-6002laminate-data-sheet.pdf

[23] https://www.macomtech.com/datasheets/MA4E1317_18 19 2160.pdf.

[24] http://www.aeroflex.com/ams/metelics/micro-metelics-prods-GaAsBeamlead-ZB.cfm

[25] www.awrcorp.com

[26] http://www.ansys.com/Products/Simulation+Technology/Electromagneti cs/Signal+Integrity+\&+Power+Integrity/ANSYS+HFSS

[27] www.feko.info

[28] Horn antenna:

$\mathrm{http} / / / \mathrm{www} . v e c t o r t e l e . c o m /$ product_VT220HA20-

SK Standard_Gain_Horn_Antenna_with_Coaxial_Connector.htm

[29] http://www.ni.com/labview/

[30] A. Takacs, H. Aubert, M. Bafleur, J.M. Dilhac, F. Courtade, S. Fredon, L. Despoisse, C.Vanhecke, G. Cluzet, "Energy harvesting for powering wireless sensor networks on-board geostationary broadcasting satellites", in Proc. of IEEE iThinghs 2012, pp. 637-640, 20-23 Nov. 2012, Besançon, France.

[31] A. Takacs, H. Aubert, L. Despoisse, S. Fredon, "Design and implementation of a rectenna for satellite application", in Proc. of IEEE WPTC'2013, pp.183-186, 15-16 May'2013, Perugia, Italy.

[32] C. Balanis, "Antenna theory analysis and design", third edition, John Wiley \& sons, 2005, chapter 2

[33] E. Falkenstein, M. Roberg, and Z. Popovic, "Low-power wireless power delivery," IEEE Trans. Microw. Theory Tech., vol. 60, no. 7, pp. 2277 2286, Jul. 2012.

[34] P.W. Hannan and M.A. Balfour, "Simulation of phase-array antenna in a waveguide", IEEE Trans. Antennas Propagat., vol. AP-13, pp. 342-353, May 1965.

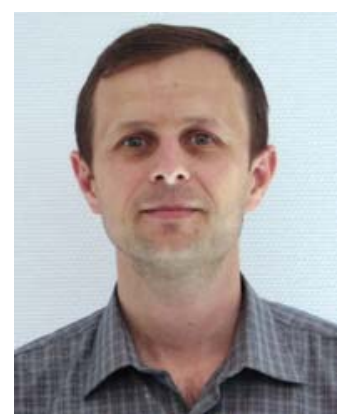

Alexandru Takacs was born in Simleu Silvaniei, Romania in March 1975. $\mathrm{He}$ received his engineer diploma in Electronic Engineering from Military Technical Academy, Bucharest, Romania in 1999, Master (2000) and Ph. D. degree (2004) in Microwave and Optical Communications from National Polytechnic Institute of Toulouse, France. From 2004 to 2007 Dr. Takacs was Lecturer at Military Technical Academy of Bucharest and Associate Researcher at Microtechnology Institute of Bucharest. He occupies a Postdoctoral position at Laboratory for Analysis and Architecture of Systems (LAAS), National Center for Scientific Research (CNRS), Toulouse France from 2008-2010. During 2011 he works as R\&D RF engineer at Continental Automotive SAS France charged with antenna design and automotive electromagnetic simulation. Since 2012, Dr. Takacs is Associate Professor at University (Paul Sabatier) of Toulouse performing his Research within CNRS, LAAS Toulouse. His research interests include: design of microwave and RF circuits, energy harvesting and wireless power transfer, MEMS circuits and systems, small antenna design, electromagnetic simulation techniques and optimization methods. He ha authored or co-authored one book, 1 book chapter, and 15 papers in refereed journals and over 70 communications in International Symposium Proceedings.

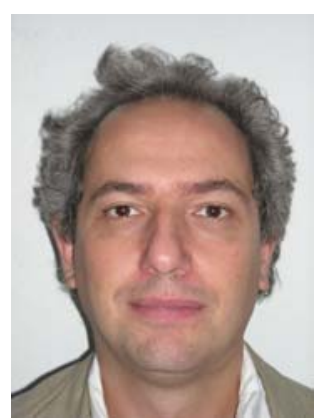

Hervé Aubert was born in Toulouse, France, in July 1966. He received the Eng. Dipl. in July 1989 and the Ph.D. degree (with high-honors) in January 1993, both in Electrical Engineering and both from the Institut National Polytechnique (INPT), Toulouse, France. Since February 2001 Hervé Aubert is Professor at INPT. He has joined the Laboratory for Analysis and Architecture of Systems (LAAS), National Center for Scientific Research (CNRS), Toulouse, in February 2006. From April 1997 to March 1998 he was a Visiting Associate Professor at the School of Engineering and Applied Science, University of Pennsylvania, Philadelphia, USA. He was co-chairman of the Electronics Laboratory of INPT from July 2001 to January 2005 and the Head of the Electromagnetics Research Group of this Laboratory from July 2002 to September 2005. From September 2004 to September 2011 Dr. Aubert was the director of the Research Master Program in Microwaves, Electromagnetism and Optoelectronics, Toulouse, France. Since January 2012 he is co-chairman of the Micro- and Nano-systems for Wireless Communications Research Group at LAAS-CNRS.

Dr. Aubert has performed research work on integral-equation and variational methods applied to electromagnetic wave propagation and scattering. Currently his research activities involve the electromagnetic modelling of complex (multi-scale) structures.

Dr. Aubert is a contributor to the books Fractals: Theory and Applications in Engineering (Springer, 1999), Micromachined Microwave Devices and Circuits (Romanian Academy Edition, 2002) and New Trends and Concepts in Microwave Theory and Techniques (Research Signpost, 2003). He has authored or co-authored one book, 2 book chapters, 71 papers in refereed journals and over 186 communications in International Symposium Proceedings. He holds 4 international patents in the area of antennas.

Dr. Aubert is expert for the French Research Agency (ANR) since 2009 and expert for the European Commission since 2012. He was the Secretary of IEEE Antennas and Propagation French Chapter from 2009 to 2013, the ViceChairman of this Chapter from 2004 to 2009 and Secretary from 2001 to 2004.

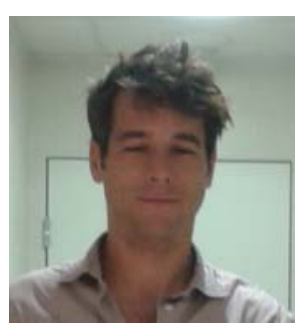

Laurent Despoisse received the Ecole Centrale de Nantes general engineer master's degree with the Command and Signal Processing specialty in 2004, and the Institut Supérieur de l'Aéronautique et de l'Espace advanced master's degree in Space Systems Engineering in 2005. From 2005 to 2007 he was Electrical Power Subsystem Engineer with Eutelsat, Paris, France, following the in-orbit telecommunication satellites' health and the new satellites procurement. From 2007 to 2008 he was Research and Development Systems Engineer with the European Space Agency, Noordwijk, The Netherlands. Since 2008 he is Electrical Power Systems Engineer with Thales Alenia Space, Cannes, France, in charge of Research and Development activities, and of Observation and Science Satellites' Electrical Power Systems Architecture and Engineering.

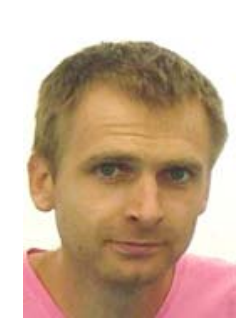

Henri Blondeaux received the Ph.D. degrees in Microwaves and Optic Communications from the University of Limoges (France) in 2001 on Radiated filters in Ka-Band supported by Thales Alenia Space. In 2001 he joined the satellite payload engineering Department of Thales Alenia Space in Cannes in charge of the Radiated Electromagnetic Compatibility (EMC) and EMI aspects from design phase to satellite test phase. Since 2006 he joined the Toulouse site of Thales Alenia Space as EMC/EMI expert on telecommunications and observations satellites and as 
expert on RF satellite tests in Compact Antenna Test Range: antennas, payload and compatibility performances. 